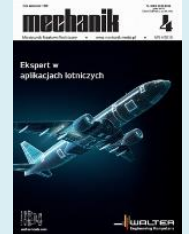

Author: Maciej Heneczkowski

Title of article: „Tendencje rozwojowe w technologii przetwórstwa tworzyw sztucznych” (“Development trends in processing of plastics")

Mechanik, Vol. 91, No. 4 (2018): pages 274-277

DOI: https://doi.org/10.17814/mechanik.2018.4.44

\title{
Development trends in processing of plastics
}

\author{
Tendencje rozwojowe w technologii przetwórstwa tworzyw sztucznych
}

\section{MACIEJ HENECZKOWSKI *}

In the manuscript current trends in the area of modification of polymer materials, including composites, new processing techniques and manufacturing managing and control systems have been described.

KEYWORDS: polymer materials, modification of polymers, processing, manufacturing managing and control systems

The plastics processing industry is a rapidly growing branch of industry, using many fields of technology: synthesis and modification of polymers, new manufacturing technologies, construction of machines and tools, information systems for designing, simulation and control of manufacturing processes and simulation of product use, i.e. mechanical stresses and the influence of the surrounding atmosphere (thermal shocks, aging under the influence of UV radiation or thermo-oxidation). Numerous advantages of plastics, resulting from their good performance and processing properties, make these materials more and more often become substitutes for traditional plastics. For these reasons, the reflections on the development trends of this industry have focused on such areas as:

- new materials, in particular polymer composites;

- innovative, environmentally friendly processing processes, including recycling;

- systems for computer simulation and processing control (in the sphere of design, processing and use of plastics);

- new, technologically advanced machines and tools;

- incremental technologies;

- systems that provide a flexible response to the individual needs of recipients and consumers.

\section{New polymer materials}

Significant progress in material engineering and polymer technology has enabled the development of new macromolecular materials with significantly higher mechanical and thermal strength, and thus with a wider range of applications.

\footnotetext{
* Dr hab. inż. Maciej Heneczkowski, prof. PRz (mhen@prz.edu.pl)

- Politechnika Rzeszowska, Zakład Kompozytów Polimerowych
}

In this respect, polymer-fiber composites play an important role, in particular carbon fiber reinforced plastics, which significantly improve mechanical strength and modulus of elasticity with a slight increase in the density of the product. In recent years, polymer-carbon composites (CFRP) have been used on a large scale in the construction of structural elements of passenger aircraft fuselages, including Boeing 787 (Dreamliner) or Airbus A350XWB.

In these models, composite elements account for $50 \%$ (Boeing) and even 53\% (Airbus) of the aircraft mass. Thanks to the use of CFRP in such a large amount, the Boeing 787 is (according to Japan Carbon Manufacturers Association [1]) $20 \%$ lighter than a traditional aircraft, containing about $3 \%$ of composites, and also emits 2700 t less $\mathrm{CO} 2$ during annual use, which corresponds to the consumption of aviation gas reduced by about $880 \mathrm{t}$ and allows to increase the range of flights. This translated into a significant reduction in the consumption of lightweight aircraft from around $70 \%$ of the aircraft's weight (in the 1990s) to around $20 \%$. In the case of cars whose bodywork would be built from CFRP, a reduction in $\mathrm{CO}_{2}$ emissions would be $0.4 \mathrm{t} / \mathrm{a}$.

A serious obstacle in the popularization of CFRP is the high price of carbon fiber and the expensive technological process of composites. For this reason, CFRP are mainly used for the production of products that must ensure good technical performance (high strength at low weight) - in this case, the price plays a smaller role. These composites are therefore used in such areas as: aviation, sports equipment, wind farms, special construction constructions or electric cars.

The hitherto traditional techniques of forming fiber composites - contact method and pultrusion - are replaced with more efficient methods and ensuring more reproducible product properties. They involve the use of prepregs, winding, pre-saturating fibers and spraying the resin.

An important issue of the use of components from CFRP (especially responsible parts of which public transport is made - for example, airplanes) is to monitor their technical condition. Different physical methods are used for this purpose:

- introduction of electric fibers into the composite - in the case of a fiber rupture, conductivity disappears,

- ultrasonic methods 
- using fiber optic sensors embedded in composite structural elements [2].

The latter of these methods allows continuous monitoring of the structure and diagnosis of its condition, which facilitates predicting even a slight deterioration of the structure of composites.

An important direction is the development of self-healing composites (SHC - self healing composites). The resin and catalyst contained in these composites are used for repair. They are enclosed in glass spheres and are released under the influence of mechanical damage of the composite - then the reaction occurs and floods the crack, due to which the element becomes ready for operation again [3].

The application of polymers is extended as a consequence of constant improvement of their properties, in particular thermal resistance and processing properties. In this case apart from the synthesis of new types of polymers, material engineering plays an important role, including development of new materials as a result of composing different polymers or other materials together, taking into account the synergistic effects between them.

It is also worth mentioning the intensive development of polymer nanocomposites, in which fillers (modified aluminosilicates, graphene, carbon nanotubes) are dispersed in the polymer matrix to nanometer sizes, which allows obtaining much higher strength of such materials $[4,5]$.

Basic trends in the field of modification of known polymers also include the preparation of new blends, which allow for the extension of the scope of application of standard materials or engineering blends with polymers belonging to a higher category (engineering and special plastics) and facilitate the processing of some macromolecular materials. This is possible due to the development of innovative methods that effectively improve the compatibility of blend components. The classic examples are even such blends as: PA/PP, PPE/PS, PPE/PP, PC/ABS, PA/PPA, PEI/PEEK.

One of the main directions of development of special polymer materials is their use in medicine - for implants, dressings, medical accessories, etc.

Fig. 1 shows the prototype of the knee joint, completely made of polymer materials, which has better operating properties (including less abrasiveness) compared to its counterparts made of metal alloys.

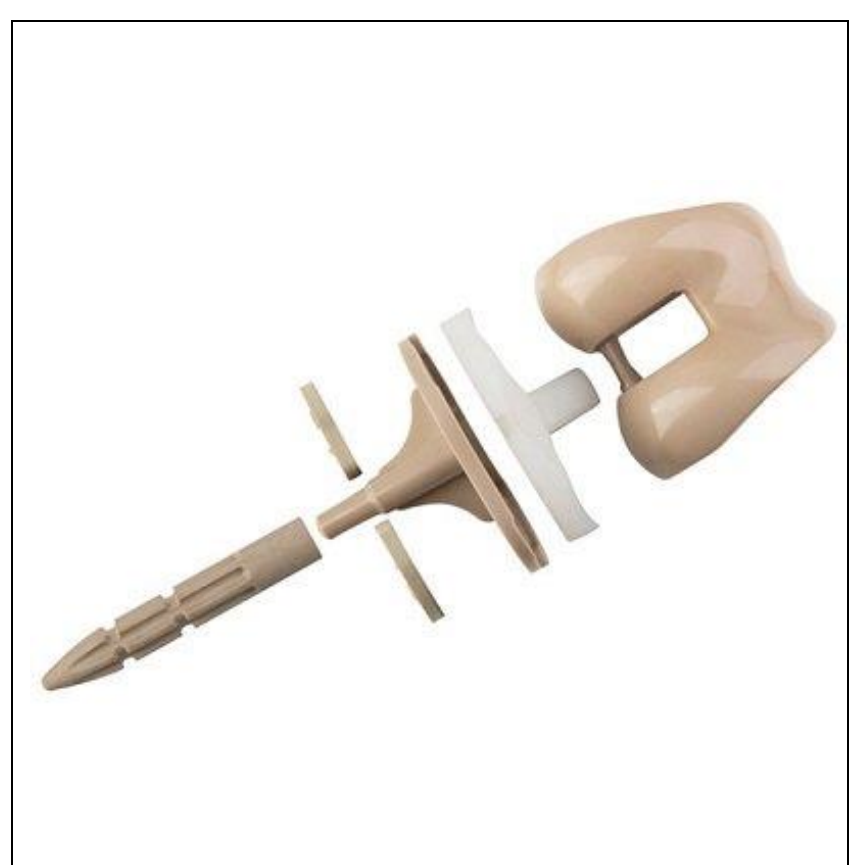

Fig. 1. Okani Medical Technology knee implant prototype made entirely of polymer materials. The main constructional elements are PEEK fittings with the trade name Zeniva [6]

\section{Environmentally friendly processing processes}

Constant emphasis on the development of production techniques that do not threaten the natural environment and allow to limit the use of natural resources also applies to the processing of plastics. You can list such trends as:

- energy-saving machines and technologies

- limiting the consumption of raw materials while retaining the functionality of products,

- shortening the time of technological operations,

- developing various forms of recycling.

Innovative processes guaranteeing less energy consumption are focused on: reducing power consumption during auxiliary operations or starting the drive, reducing heat losses, shortening some technological operations or changing tools. For injection molds, electromagnetic mounting systems and unified connection of cooling media or power supply have been developed. In the case of injection molding machines, the reduction of energy consumption is achieved by the use of electric or hybrid machines (hydraulicelectric) and the introduction of cylinder heating insulation. The way to increase the efficiency of hydraulic injection molding machines was the introduction of hydraulic accumulators and servo drives, which accelerated the performance of technological operations and ensured energy savings. The development of blow molding machines is also in a similar direction

The reduction of plastics consumption is ensured by gas assisted injection molding (GAIM) or water assisted injection molding (WAIM) technologies and microcellular foam injection molding (MuCell - plastic injection with supercritical gas injected into the plasticizing cylinder). It should be emphasized that for economic reasons GAIM technology is developed much more than WAIM. These techniques also allow to shorten the cooling time of the moldings and reduce the injection pressure and clamping force of the injection molding machine necessary to carry out the process. Due to the simultaneous use of MuCell technology and the system of quick heating and cooling of cavities (RHCM), the basic primary disadvantage of this technology has been eliminated - inferior gloss of molding parts in relation to shapes injected traditionally. Currently, machines suitable for this technique are offered by all significant manufacturers of injection molding machines.

The MuCell Extrusion LLC company offers extrusion lines for films or plates using the mutation of MuCell technology. Other variants of the film extrusion process are based on a solution that allows to reduce its thickness by using the Alpha Marathon Film Extrusion Technologies Inc. developed by Alpha Marathon, die with modular discs in which the melt flow is divided into many layers of small thickness (nanolayers) [7]. In this way, the thickness of the film can be reduced by approx. $25 \%$ in relation to the film made in a typical technology. Extrusion of pipes composed of several (two or three) layers, of which the inner one can be made of glass fiber reinforced plastic, and the rest - of non-reinforced material, improves the product's operational properties. Similarly, you can make boards or films in which the inner layer is recycled. Such products in which the recyclate is isolated by the starting polymer layer can be used in articles in contact with food.

In recent years, many more environmentally friendly technologies for processing finished products have also been developed, e.g. metallization by means of vacuum coating of plastic details (sputter deposition), which is an alternative to the previously used electrochemical metallization (in this method, obtaining a final coating of metallic chromium required the use of baths with toxic compounds of this element in the oxidation state $\mathrm{VI}$ ). In turn, to improve the barrier of packaging materials (PET), their surface is coated with $\mathrm{SiO}_{2}$ in the presence of low temperature plasma. 
The biggest research challenge in the field of recycling plastics is the management of waste polymer-fiber composites in which the matrix is cross-linked resins. In the scientific literature, this topic often appears because it is also important from an economic and ecological point of view.

One of the issues is the recycling of car tires. Used tires are often intended for burning in cement kilns, because they have a high calorific value. However, projects are being undertaken in which, as a result of pyrolysis caused by various factors - superheated steam, ultrasounds or microwave radiation - the polysulfide bonds are cracked, the rubber chains are recovered and they are destined for reprocessing. Such a product, however, is contaminated with sulfur derivatives, which limits its use, therefore work is underway to remove this defect. In the case of waste polymer-carbon construction composites, carbon fiber is a very valuable raw material. Several dozen works have appeared on the subject of recovery of these raw materials in recent years, in which various ways of separating the hardened polymer from carbon fiber have been described, but for now these projects have only reached the laboratory scale.

Recently, plastics based on polymers - such as polylactide, poly (glycolic acid) or modified natural polymers - have intensively developed with reinforcement from hemp fibers, sisal fibers, flax fibers, etc. They are obtained or obtained from renewable sources. The advantage of these materials is their biodegradability, which makes them particularly suitable for products with a short service life (e.g for disposable dishes, disposable packaging) and do not constitute a long-term environmental burden as postconsumer waste.

\section{Computer aided engineering (CAE) systems}

In the era of intensive development of computer science and control of design and manufacturing processes, these tools have entered very strongly into the processing of plastics. This applies in particular to: injection molding, extrusion pressing and extrusion, molding of composites, and more recently - also thermoforming.

In order to design the shape and load simulation of injection parts, most of the available CAD programs are used: CATIA, NX, Pro/Engineer, Autodesk Inventor, etc. Autodesk Moldflow Insight (AMI), CADMOULD, Moldex3D and SIGMA Soft programs are used to simulate injection molding. Quickly implemented modifications to the injection technology are gradually updated to keep up with the changes and face competition.

There is also a tendency to combine these programs with CAD systems. In this way, the oldest Moldflow simulation program was bought by Autodesk, which allowed its integration with other products of the current owner. This facilitates the design of injection molds using Autodesk Inventor and transferring results to strength calculations (in the Nastran program). Similar activities were undertaken by CoreTech (owner of Moldex3D) and Siemens PLM Software (owner of NX) - under their agreement Moldex3D was integrated with the NX system, starting from version NX 8.5.

Modern injection molding machines are equipped with sensors monitoring the temperature and/or pressure of mold cavities, as well as control systems that allow for current control of the filling state of the seat and proper adjustment of the machine settings or elimination of defective fittings produced with wrong parameters.

An example of such a system is Priamus, intended mainly for the production of fittings with increased accuracy. Leading injection molding machines use systems based on a similar idea, guaranteeing current, statistical process control adapted to coordination with remote production control. All these activities are within the so-called the fourth industrial revolution - Industry 4.0 .
The same applies to extrusion, for which several commercial programs for tool design and process control have been developed: ANSYS Polyflow, COMPUPLAST VEL, polyXtrue, LabVIEW and ERP (for profile extrusion).

\section{Additive technologies - a threat or enrichment of traditional processing methods?}

Additive techniques (rapid prototyping), which initially were supposed to facilitate and accelerate the production of prototypes, quickly developed and became a very flexible method of producing tools (rapid tooling) and short series of products (rapid manufacturing). Methods such as FDM or SLS are often used to produce a small number of details from plastics, but they enable quick modification of the shape of these details without the need to change tools. The high flexibility of incremental technologies allows for easy adaptation of product features to the needs and requirements of customers. These methods effectively compete with injection, extrusion, thermoforming, etc., so with processes in which any change in the characteristics of the product requires modification of tools (e.g. mold, head), which is usually expensive and time-consuming. One should therefore expect further development of incremental technologies.

Additive technologies, especially those from the rapid tooling group - e.g. laser sintering of metal powders (DMLS) - enable the production of very geometrically complicated mold cavities and obtaining shape-adapted moldings for cooling channels or forming cores - so-called. conformal channels (fig. 2) [2]. In these cases, the incremental technologies ensure greater injection efficiency due to more even cooling of the moldings and shortening of the cycle time in molds equipped with conformal channels.

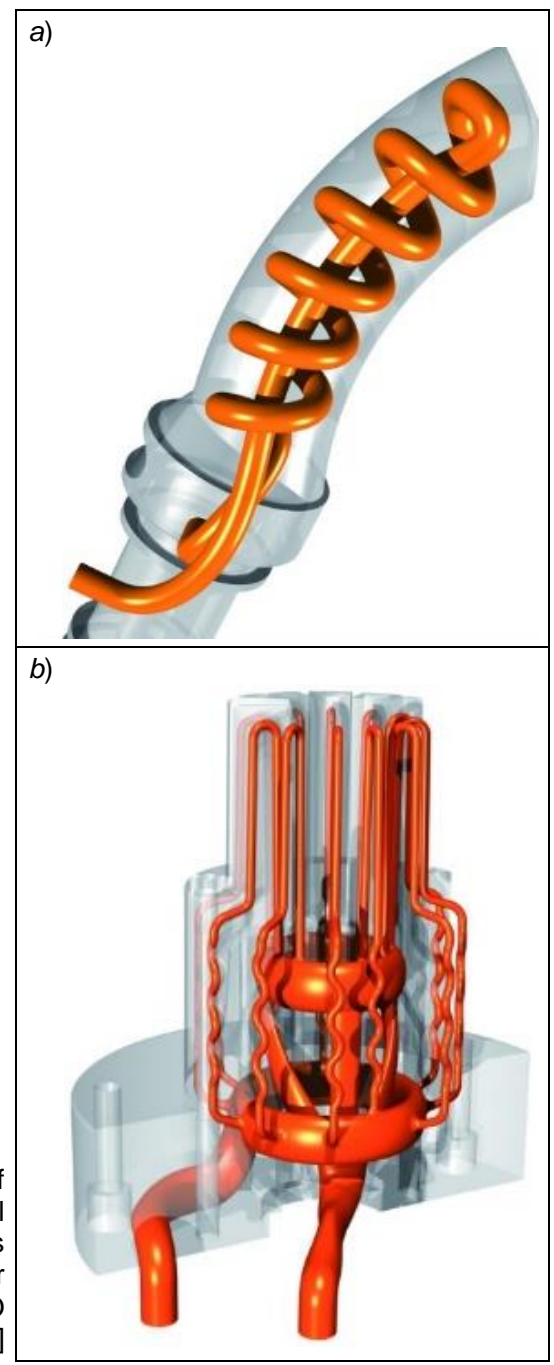

Fig. 2. Example of fittings with conformal conformal channels adapted to their geometry - FADO solution [2] 


\section{Information technology that provides a flexible response to market needs}

Another factor, definitely entering into plastics processing and causing a more effective and flexible response to the highly individualized requirements of customers, is full computerization of the manufacturing process. It is implemented through such systems as:

- SPC system (statistical process control) - a program for continuous product quality assessment, consisting in continuous monitoring of technological parameters and checking if they are within acceptable limits. The combination of this data in the IT system allows for the elimination of defective products and prevents the need to check product quality by randomly;

- MES production system (Manufacturing Execution System) - allows for current collection, collection and selection of information on the status of individual production processes directly, practically from all workplaces. Due to this, the dispatcher can view the data on the status of orders and can control the changes of individual material streams. This system is usually correlated with MRP and ERP;

- Material Requirements Planning (MRP) and Enterprise Resources Planning (ERP) - MRP defines procedures for raw materials, materials, components, etc., while ERP includes IT systems to support the management of the enterprise or companies constituting the supplier chain, i.e. collecting systems needed for individual units and allowing them to be processed.

Matching products manufactured to the individual requirements of different customers is possible due to the introduction of the so-called intelligent robots responding to current needs. This is the main direction of changes in the production organization in accordance with the Industry 4.0 rules.

\section{REFERENCES}

1. www.carbonfiber.gr.jp/english/tech/lca.html.

2. www.immt.pwr.wroc.pl/ gasior/hpvl/KMP\%20\%20Aplikacja\%2 0\%C5\%9Bwiat\%C5\%82owodowych\%20metod\%20czujnikowy ch\%20do\%20monitorowania\%20ekstremalnie\%20wyt\%C4\%9 9\%C5\%BConych\%20konstrukcji\%20kompozytowych.pdf.

3. Wang Y., Pham T.D., Ji C. "Self-healing composites: A review". Materials Engineering. 2 (2015), 1075686.

4. Bhattacharya M. "Polymer nanocomposites - A comparison between carbon nanotubes, graphene, and clay as nanofillers". Materials. 9 (2016): p. 262.

5. Yurddaskal M., Celik E. "Effect of halogen-free nanoparticles on the mechanical, structural, thermal and flame retardant properties of polymer matrix composite". Composite Structures. 183, 1 (2018): pp. 381-388.

6. https://omnexus.specialchem.com/news/industry-news/solvaypeek-okani-medical-all-polymer-knee-implant$000213766 ? \mathrm{l}=\mathrm{r}=\mathrm{iom} 18031715 \& \mathrm{li}=100212492 \& u t m \_s o u r c e=N L \&$ utm_medium $=E M L \& u t m \_$campaign=iom $1803171 \overline{5} \& \mathrm{~m} \_\mathrm{i}=\mathrm{CFoC}$ DilYR_cKIwFUpJVAy6JPrlx1vlr8a9qDqYFbeBIxNVBwabyzPU IllaPQZZGHQwA8FfUULOv3BJpegq3eaqO5J1scZCa.

7. www.alphamarathon.biz/alpha-exclusive-technologies/alpha-spatented-annular-nano-layer-die.html.

8. www.fado.info/oferta/chlodzenie-konformalne.

Translation of scientific articles, their computer composition and publishing them on the website www.mechanik.media.pl by original articles in Polish is a task financed from the funds of the Ministry of Science and Higher Education designated for dissemination of science. 